\title{
Investigation on Pulmonary Tuberculosis Among Bedele Woreda Prisoners, Southwest Ethiopia
}

\author{
Bula Boru Winsa, Abdurehman Eshete Mohammed* \\ Department of Medical Laboratory Sciences and Pathology, College of Health sciences, Jimma University, Ethiopia
}

Email address:

bula_boru@yahoo.com (Bula Boru Winsa), aeshete8@gmail.com (Abdurehman Eshete Mohammed)

To cite this article:

Bula Boru Winsa, Abdurehman Eshete Mohammed. Investigation on Pulmonary Tuberculosis Among Bedele Woreda Prisoners, Southwest Ethiopia. International Journal of Biomedical Science and Engineering. Vol. 3, No. 6, 2015, pp. 69-73. doi: 10.11648/j.ijbse.20150306.11

\begin{abstract}
Back ground: Tuberculosis (TB) is an airborne infectious disease. One third of the world population is infected with Mycobacterium. Ethiopia ranks $8^{\text {th }}$ among the world's top 22 countries severely affected by TB.TB is recognized as a major public health problem in the prisons of sub-Saharan Africa and it remains one of the leading cause of morbidity and mortality worldwide especially in resource limited countries. Purpose: To determine the prevalence and associated risk factors of pulmonary tuberculosis among Bedele woreda prisoners. In addition to this, it will increase the awareness of the prisoners about tuberculosis and used as baseline data for the concerned bodies for the control and prevention of tuberculosis in the prison population. Methods: An institution based cross-sectional study was conducted in Bedele woreda prison and a total of 196 prisoners were enrolled in this study. All suspected prisoners; who had cough for two weeks and more were included. The sputum was collected spot morning spot with screw caped plastic container and sodium hypochlorite technique was used to concentrate the bacilli and stained with Ziehl-Neelsen staining technique. The data was analyzed using SPSS version 20 software. Bivariate and multivariate logistic regressions were computed and P-value $<0.05$ was used as statically significance. Result: Out of 196 prisoners screened for pulmonary tuberculosis, 43(21.9\%) of the prisoners were positive for Acid Fast Bacilli (AFB). The minimum and maximum age was 18 and 80 respectively. Most of the AFB positive prisoners were male. In multivariate binary logistic regression analysis associated risk factors like cough $\geq 2$ weeks $(\mathrm{AOR}=0.016,95 \% \mathrm{CI}$ : 0.002-0.114, $\mathrm{P}$ value $<0.05$ ) and history of TB in the group ( $\mathrm{AOR}=0.003,95 \% \mathrm{CI}$ : $0.000-0.033, \mathrm{P}$ value $<0.05$ ) had significant association with pulmonary tuberculosis. Conclusion: We conclude that a high prevalence of pulmonary tuberculosis was seen in Bedele woreda prisoners, which was greater than the general population.
\end{abstract}

Keywords: Tuberculosis, Prisoners, Ethiopia

\section{Introduction}

The genus Mycobacterium consists of non motile, non spore-forming aerobic acid-fast bacilli. The cell wall is lipophilic and resistant to many disinfectants as well as to common laboratory stains. Currently, more than 70 species of Mycobacterium have been identified, many of which are associated with human diseases [1]. Tuberculosis (TB) remains a major global public health problem. It is estimated that about one-third of the world's population is infected with Mycobacterium tuberculosis. There were an estimated 9 million new cases of TB, resulting in 1.5 million deaths, with the greatest burden of disease in developing nations [2].

Tuberculosis (TB), one of the most important contagious diseases, is a leading cause of death due to a single pathogen worldwide. Patients with pulmonary TB would broadcast the tubercle bacilli in droplet aerosols as they cough, sneeze, or even talk and infect those in contact. A person with untreated pulmonary TB is estimated, on average, to infect 10-15 persons annually. A primary infection due to Mycobacterium tuberculosis may actively develop into clinical TB, pass as in apparent infection, or remain latent in the individual for months or years depending on the various host and environmental factors. Overt TB, thus, could result from a reactivated latent infection or from a recent primary infection or (secondary) re-infection. It has been observed that the transmission of $\mathrm{M}$. tuberculosis is favored by dusty environment, poor ventilation, little sun light, malnourished, back ground of alcohol and drug abuse, overcrowding, relative virulence of the strain, the intensity of exposure to an infectious TB case (closeness and duration), and the susceptibility and immune status of the exposed individual[34]. 
Occurrence of active tuberculosis (TB) in prisons is usually reported to be much higher than the average levels reported for the corresponding general population. In prisons located in developing countries TB has been reported as the most common cause of death. High levels of TB in prison populations are likely to be attributable to the fact that a disproportionate number of prisoners are from population groups already at high risk of TB infection and TB disease .Furthermore, the prison setting, where segregation criteria are based on crime characteristics rather than on public health concerns, may facilitate transmission. In addition, late case detection, inadequate treatment of infectious cases, high turnover of prisoners, and poor implementation of TB infection control measures are all known factors contributing to transmission of Mycobacterium tuberculosis [5-10].

On any day worldwide about 10 million people are incarcerated, in prisons, remand centers, police stations, jails, detention centers for asylum seekers, penal colonies, and prisoner of war camps. There is an increasing recognition that the high risk of tuberculosis in these settings poses a problem for those imprisoned and for the wider society [11].

Prisons represent a crucial setting for tuberculosis (TB) control. Worldwide, 10-100-times higher rates have been reported for $\mathrm{TB}$ in correctional systems than in the local civilian populations, and out breaks have also been documented. Regardless of the pattern of TB spread among prisoners, i.e. endemic cases versus outbreaks, TB has repeatedly been shown to also involve the prison staff and the surrounding community, to the extent that the World Health Organization recently stated that "prisons act as a reservoir for TB, pumping the disease into the civilian community through staff, visitors and inadequately treated released [12]

Tuberculosis (TB) is recognized as a major public health problem in the prisons of sub-Saharan Africa. Tuberculosis (TB) remains one of the leading causes of mortality, morbidity and health-related socioeconomic problems worldwide, especially in resource poor countries. Ethiopia ranks seventh among the world's top 22 countries and $3^{\text {rd }}$ in Africa severely affected by TB, with an estimated incidence rate of 378 cases per 100 000population in 2007. Although the DOTS strategy was implemented nearly two decades ago, its current geographic coverage and case detection rate remain low, and are challenged by extended delays in diagnosis and treatment $[13,14]$.So, this study was conducted to determine the prevalence and associated risk factors of Pulmonary Tuberculosis among Bedele Woreda prisoners.

\section{Materials and Methodology}

\subsection{Study Area}

The study was conducted in Bedele town prison, which is found in Oromia region, Ilubabor zone, Bedele town Woreda; the town is located $423 \mathrm{~km}$ southwest of the capital Addis Ababa. This town has a longitude and latitude of $8^{\circ} 27^{\prime} \mathrm{N}$ $36^{\circ} 21^{\prime} \mathrm{E}$ and an elevation between 2,012-2,162 meters $(6,601-7,093 \mathrm{ft})$ above sea level. Total population for Bedele were 19,517, of whom 9,837 were men and 9,680 were women Bedele prison has a total of five hundred prisoners and seven cells. The town has a characteristic of tropical highland climate condition, heavy rain fall, warm temperature, and long wet period [15].

\subsection{Study Design and Subjects}

An institutional-based cross-sectional study was conducted from February 1-30, 2012. A total of 196 prisoners were participated in this study. All suspected prisoners who had cough for two weeks and more were included in the study.

\subsection{Data Collection Procedures}

Data from socio-demographic and associated risk factors were collected using predesigned questionnaire by trained medical laboratory technologists. A $1-2 \mathrm{ml}$ of sputum (particularly that which contains any yellow caseous material) that were collected spot morning spot was transferred to a $15-20 \mathrm{ml}$ capacity of test tube and an equal amount 5\% sodium hypochlorite (bleach) solution was added and mixed well. Then it leaves at room temperature for 15 minutes, shaking at intervals to break down the mucus in the sputum, $8 \mathrm{ml}$ of distilled water is added and centrifuge at 3000 RPM for 15 minutes. The supernatant fluid was discarded with pasture pipette and the sediment was mixed well, a drop of the mixed-well sediment was transferred to a clean scratch-free microscopic slide, spread the sediment to make a thin preparation and allow air-drying, heat-fix the smear and stain it using Ziehl- Neelsen staining technique. Finally the stained slides were examined microscopically for Acid Fast Bacilli (AFB) as described by [16].

\subsection{Data Analysis}

The result was noted on data collection format. Finally the data was edited and entered into computer and analyzed using SPSS version 20.00 windows software. Descriptive statistics, Chi-square test, bivariate and multivariate logistic regressions were used for the analysis, taking $\mathrm{P}$ values less than 0.05 considered as significant. All the sociodemographic and associated risk factors were tested by bivariate binary logistic regression and whose values less than 0.25 were candidate for multivariate binary logistic regression analysis.

\subsection{Ethical Consideration}

Ethical clearance was obtained from Jimma University and Bedele woreda prison administrators. The purpose of the study was clearly explained for the study subjects, and written consent was obtained from each study participants. Confidentiality of the result was kept by coding patient information and specimen. 


\section{Result}

\subsection{Socio-Demographic Characteristics}

Out of 196 prisoners screened for pulmonary tuberculosis (PTB), 43(21.9\%) of the prisoners were positive for Acid Fast Bacilli (AFB). The minimum and maximum age was 18 and 80 respectively. The age group 15-24, 19(44.2\%) was the most affected age group. Most of the Acid Fast Bacilli (AFB) positive prisoners were male which accounts about $42(95.3 \%)$. In relation to the origin of the prisoners, $29(67.4 \%)$ of them were come from rural and the duration of the majority of the prisoners in the prison who were positive for AFB, 34(79.1\%) were less than one year. Twenty seven $(62.8 \%)$ of the AFB positive prisoners were farmer before they join the prison. In educational status, $14(32.6 \%)$ of illiterate prisoners were AFB positive. Duration of the prisoners in the prison had significant association with PTB by Pearson's chi-square test $(\mathrm{p}<0.05)$. (Table 1$)$

\subsection{Risk Factors Associated with Pulmonary Tuberculosis (PTB)}

The overall prevalence of PTB in this study was
43(21.9\%). Most of the AFB positive prisoners, 38(88.4\%) had cough greater than three weeks and almost all of the prisoners who were positive for AFB had no family history of tuberculosis. Twenty three $(53.5 \%)$ of the prisoners who were positive for AFB, were members of the group who had TB previously in the group. The prisoners, $58.1 \%$ who were live in cells which contain 56-75 prisoners were more affected by PTB. All of the AFB positive prisoners were live in cells which had one window. Five (11.6\%) of the AFB positive prisoners had previous history of TB. There were one known diabetic and one known HIV sero-positive prisoners who were positive for AFB. Cough greater than three weeks, TB from the group in the prison previously and number of windows in one cell had significant association with PTB by Pearson's chi-square test $(\mathrm{p}<0.05)$. (Table 2)

In bivariate and multivariate binary logistic regression analysis risk factors like cough greater than three weeks(AOR $=0.016,95 \%$ CI:0.002-0.114, $\mathrm{P}$ value $<0.05$ ) and anybody who had $\mathrm{TB}$ from the group previously ( $\mathrm{AOR}=0.003$, $95 \%$ CI:0.000-0.033, $\mathrm{P}$ value $<0.05)$ had significant association with pulmonary tuberculosis (Table 3 ).

Table 1. Socio-demographic characteristics vs. AFB result $(n=196)$ at Bedele prison, 2012.

\begin{tabular}{|c|c|c|c|c|c|c|}
\hline \multirow{2}{*}{ Characteristics } & & \multicolumn{3}{|l|}{ Result } & \multirow{2}{*}{ Chi-square } & \multirow{2}{*}{ P-value } \\
\hline & & Positive (\%) & Negative (\%) & Total & & \\
\hline \multirow{5}{*}{ Age } & $15-24$ & $19(44.2)$ & $67(43.8)$ & $86(43.9)$ & \multirow{5}{*}{0.179} & \multirow{5}{*}{0.996} \\
\hline & $25-34$ & $13(30.2)$ & $43(28.1)$ & $56(28.6)$ & & \\
\hline & $35-44$ & $5(11.6)$ & $18(11.8)$ & $23(11.7)$ & & \\
\hline & $45-54$ & $2(4.7)$ & $8(5.2)$ & $10(5.1)$ & & \\
\hline & $\geq 55$ & $4(9.3)$ & $17(11.1)$ & $21(10.7)$ & & \\
\hline \multirow{2}{*}{ Gender } & Male & $41(95.3)$ & $143(93.5)$ & 184(93.9) & \multirow{2}{*}{0.207} & \multirow{2}{*}{0.649} \\
\hline & Female & $2(4.7)$ & $10(6.5)$ & $12(6.1)$ & & \\
\hline \multirow{2}{*}{ Origin of the prisoner } & Urban & $14(32.6)$ & $30(19.6)$ & $44(22.4)$ & \multirow{2}{*}{3.234} & \multirow{2}{*}{0.072} \\
\hline & Rural & $29(67.4)$ & $123(80.4)$ & $152(77.6)$ & & \\
\hline \multirow{6}{*}{$\begin{array}{l}\text { Duration of the prisoner } \\
\text { in the prison }\end{array}$} & $<1$ year & $34(79.1)$ & $102(66.7)$ & $136(69.4)$ & \multirow{6}{*}{12.596} & \multirow{6}{*}{0.027} \\
\hline & $1-2$ years & $3(7.0)$ & $33(21.6)$ & $36(18.4)$ & & \\
\hline & $2-3$ years & $3(7.0)$ & $1(.7)$ & $4(2.0)$ & & \\
\hline & $3-4$ years & $1(2.3)$ & $10(6.5)$ & $11(5.6)$ & & \\
\hline & $4-5$ years & $1(2.3)$ & $2(1.3)$ & $3(1.5)$ & & \\
\hline & $>5$ years & $1(2.3)$ & $5(3.3)$ & $6(3.1)$ & & \\
\hline \multirow{5}{*}{$\begin{array}{l}\text { Occupation before they } \\
\text { join the prison }\end{array}$} & Farmer & $27(62.8)$ & $113(73.9)$ & $140(71.4)$ & \multirow{5}{*}{6.186} & \multirow{5}{*}{0.186} \\
\hline & Merchant & $1(2.3)$ & $6(3.9)$ & $7(3.6)$ & & \\
\hline & Employed & $1(2.3)$ & $1(.7)$ & $2(1)$ & & \\
\hline & Unemployed & $7(16.3)$ & $9(5.9)$ & $16(8.2)$ & & \\
\hline & Student & $7(16.3)$ & $24(15.7)$ & $31(15.8)$ & & \\
\hline \multirow{4}{*}{ Educational status } & Illiterate & $14(32.6)$ & $63(41.2)$ & $77(39.3)$ & \multirow{4}{*}{1.045} & \multirow{4}{*}{0.307} \\
\hline & 1-4 grade & $12(27.9)$ & $35(22.9)$ & $47(24)$ & & \\
\hline & $5-8$ grade & $13(30.2)$ & $36(23.5)$ & $49(25)$ & & \\
\hline & $9-12$ grade & $4(9.3)$ & $20(13.1)$ & $24(12.2)$ & & \\
\hline
\end{tabular}

Table 2. Associated risk factors vs. AFB result $(n=196)$ at Bedele prison, 2012.

\begin{tabular}{|c|c|c|c|c|c|c|}
\hline \multirow{2}{*}{ Variables } & & \multicolumn{3}{|l|}{ Result } & \multirow{2}{*}{ Chi-square } & \multirow{2}{*}{ P-value } \\
\hline & & Positive (\%) & Negative (\%) & Total (\%) & & \\
\hline \multirow{2}{*}{ Cough $\geq 2$ weeks } & Yes & $38(88.4)$ & $47(30.7)$ & $85(43.4)$ & \multirow{2}{*}{45.428} & \multirow{2}{*}{0.001} \\
\hline & No & $5(11.6)$ & $106(69.3)$ & $111(56.6)$ & & \\
\hline \multirow{2}{*}{ Family history of TB } & Yes & $5(11.6)$ & $11(7.2)$ & $16(8.2)$ & \multirow{2}{*}{0.882} & \multirow{2}{*}{0.348} \\
\hline & No & $38(88.4)$ & $142(92.8)$ & $180(91.8)$ & & \\
\hline
\end{tabular}




\begin{tabular}{|c|c|c|c|c|c|c|}
\hline \multirow{2}{*}{ Variables } & & \multicolumn{3}{|l|}{ Result } & \multirow{2}{*}{ Chi-square } & \multirow{2}{*}{ P-valu } \\
\hline & & Positive (\%) & Negative (\%) & Total (\%) & & \\
\hline \multirow{2}{*}{$\begin{array}{l}\text { Anybody have TB from the } \\
\text { group previously }\end{array}$} & Yes & $23(53.5)$ & $3(2)$ & $26(13.3)$ & \multirow{2}{*}{77.459} & \multirow{2}{*}{0.001} \\
\hline & No & $20(46.5)$ & $150(98)$ & $170(86.7)$ & & \\
\hline \multirow{6}{*}{ Number of prisoner in one class } & $1-15$ & $4(9.3$ & $25(16.3$ & $29(14.8$ & \multirow{6}{*}{8.042} & \multirow{6}{*}{0.154} \\
\hline & $16-30$ & $7(16.3$ & $23(15$ & $30(15.3$ & & \\
\hline & $31-45$ & $5(11.6)$ & $36(23.5)$ & $41(20.9)$ & & \\
\hline & $46-55$ & $1(2.3)$ & $9(5.9)$ & $10(5.1)$ & & \\
\hline & $56-75$ & $25(58.1)$ & $56(36.6)$ & $81(41.3)$ & & \\
\hline & $>75$ & $1(2.3)$ & $4(2.6)$ & $5(2.6)$ & & \\
\hline \multirow{2}{*}{ Number of window in one class } & One & $43(100$ & $135(88.2$ & $178(90.8$ & \multirow{2}{*}{5.570} & \multirow{2}{*}{0.018} \\
\hline & Zero & 0 & $18(11.8)$ & $18(9.2)$ & & \\
\hline \multirow{2}{*}{ Previous history of TB } & Yes & $5(11.6)$ & $9(5.9)$ & $14(7.1)$ & \multirow{2}{*}{1.671} & \multirow{2}{*}{0.196} \\
\hline & No & $38(88.4)$ & $144(94.1)$ & $182(92.9)$ & & \\
\hline \multirow{2}{*}{ History of Diabetes Mellitus } & Yes & $1(2.3)$ & $1(0.7)$ & $2(1)$ & \multirow{2}{*}{0.929} & \multirow{2}{*}{0.335} \\
\hline & No & $42(97.7)$ & $152(99.3)$ & 194(990 & & \\
\hline \multirow{2}{*}{ History of HIV AIDS } & Yes & $1(2.3)$ & 0 & $1(0.5)$ & \multirow{2}{*}{3.576} & \multirow{2}{*}{0.059} \\
\hline & No & $42(97.7)$ & $153(100)$ & $195(99.5)$ & & \\
\hline
\end{tabular}

Table 3. Bivariate and multivariate analysis of associated risk factors (n=196) at Bedele prison, 2012.

\begin{tabular}{lllllllll}
\hline Characteristics & & Frequency (\%) & COR & $\mathbf{9 5 \%}$ CI & P-value & AOR & 95\% CI & P-value \\
\hline \multirow{2}{*}{$\begin{array}{l}\text { Cough } \geq 2 \text { weeks } \\
\text { History of TB from the }\end{array}$} & Yes & $85(43.4)$ & 0.058 & $0.022-0.158$ & 0.001 & 0.016 & $0.002-0.114$ & 0.001 \\
group & Yes & $111(56.6)$ & 1 & & & 1 & \\
& No & $17(13.3)$ & 0.017 & $0.005-0.063$ & 0.001 & 0.003 & $0.000-0.033$ \\
\hline
\end{tabular}

COR: crude odds ratio, AOR: adjusted odds ratio, $\mathrm{CI}$ : confidence interval

\section{Discussion}

Ethiopia was ranked eighth in the burden of Tuberculosis (TB) disease by global tuberculosis report of 2012 [17]. The prevalence of pulmonary tuberculosis (PTB) in the general population was $10.62 \%$ [18]. Where as in this study, the prevalence of PTB was $21.9 \%$, which was two-times higher than the general population PTB prevalence.

The prevalence of this study was higher than the studies conducted in Bangladesh $13.8 \%$ [9], Cameron 1.2\% [13], Brazil 2.5\% [19], Iran 0.91\% [20], Malawi 0.7\% [22] and North Gonder, Ethiopia 8.9\% [23]. On the other hand, the prevalence of this study was lower than the studies conducted in Nigeria 54.2\% [4] and Pakistan $26.3 \%$ [21].

The above difference in the prevalence of PTB was may be due to the number of prisoners in the prison, the number of prisoners in one cell, the functionality and number of windows in one cell, the general health condition of the prisoners, availability of health facility in the prison and the environmental conditions of the prison. Despite the above difference the prevalence of this study is comparable to the study done in Gamo Goffa Zone, south Ethiopia 19.4\% [24].

In this study cough had significant association with PTB infection, which is consistent with the study done in Brazil [19] and almost all acid fast bacilli (AFB) positive prisoners were had no history of TB, which is consistent with the study conducted in Iran [20].

Most of the prisoners who were participated in this study were literates (who can read and write) which were different with the study conducted in Pakistan [21]. Also, most of the prisoners who were participated in this study were males, which was consistent with the studies reported in Brazil [19], Iran [20] and Malawi [22].

\section{Conclusion}

We conclude that a high prevalence of pulmonary tuberculosis was seen in Bedele woreda prisoners, which was greater than the general population. Pre-screening of newly coming prisoners before joining the prison and organizing health facility which used for diagnosis and treatment of PTB suspected prisoners within the prison might be useful.

\section{Author Contributions}

All authors contributed toward data analysis, drafting and revising the paper.

\section{Acknowledgment}

We thank Jimma University for material support, Bedele woreda prison administrators for their cooperation and Bedele woreda prisoners who were involved in this study. We also thankful Mr. Dereje Atomsa Ayele who helps us in clinical specimen analysis.

\section{References}

[1] Murray, P.R, Rosental, K.S, Kobayash, G.S, Pfaller, M.A (2002). Medical Microbiology. $4^{\text {th }}$ edition. St. Louis, Mo, USA.

[2] WHO (2014). Tuberculosis Report. 
[3] Bergmire-Sweat, D., Barnett, B.J, Harris, S.L., Taylor, J.P., Mazurek, G.H., Reddy, V (1996). Tuberculosis outbreak in a Texas prison, 1994 ; 117:485-92.

[4] Chigbu, L. N. and Iroegbu, C.U. (2010). Incidence and Spread of Mycobacterium tuberculosis-associated Infection among Aba Federal Prison Inmates in Nigeria. J Health Popul Nutr; 28: $327-332$.

[5] Legrand, J., Sanchez, A., Le Pont, F., Camacho, L., Larouze, $\mathrm{B}(2008)$.Modeling the Impact of Tuberculosis Control Strategies in Highly Endemic Overcrowded Prisons. PLoS ONE ; 3: e2100.

[6] Vieira, A.A, Ribeiro, S.A, De Siqueira, A.M, Galesi, V.M, Dos Santos, L.A, Golub JE(2010). Prevalence of patients with respiratory symptoms through active case finding and diagnosis of pulmonary tuberculosis among prisoners and related predictors in a jail in the city of Carapicuíba, Brazil. Rev Bras Epidemiol; 13:641-50.

[7] Baussano I, Williams BG, Nunn P, Beggiato M, Fedeli U, et al(2010). Tuberculosis Incidence in Prisons: A Systematic Review. PLoS Med; 7: e1000381.

[8] The PLoS Medicine Editors (2010). The Health Crisis of Tuberculosis in Prisons Extends beyond the Prison Walls. PLoS Med; 7: e1000383.

[9] Banu S, Hossain A, Uddin MKM, Uddin MR, Ahmed T, et al(2010). Pulmonary Tuberculosis and Drug Resistance in Dhaka Central Jail, the Largest Prison in Bangladesh. PLoS ONE; 5: e10759.

[10] Pfyffer GE, Strässle A, van Gorkum T, Portaels F, Rigouts L, Mathieu C, etal(2001). Multidrug-resistant tuberculosis in prison inmates, Azerbaijan. Emerg Infect Dis; 7:855-61.

[11] Coninx R, Maher D, Reyes H, and Grzemska M (2000). Tuberculosis in prisons in countries with high prevalence. BMJ; 320: 440-442.

[12] Carbonara S, Babudieri S, Longo B , Starnini G, Monarca R , Brunetti B etal(205)._Correlates of Mycobacterium tuberculosis infection in a prison population. European Respiratory Journal; 25: 1070-1076.

[13] Noeske J, Ndi N, Mbondi S (2011). Controlling tuberculosis in prisons against confinement conditions: a lost case? Experience from Cameroon. The International Journal of Tuberculosis and Lung Disease; 15: 223-227.
[14] Abebe DS, Biffa D, Bjune G, Ameni G, Abebe F(2011). Assessment of knowledge and practice about tuberculosis among eastern Ethiopian prisoners. Int J Tuberc Lung Dis; 15:228-33.

[15] Federal Democratic Republic of Ethiopian Population Census Commission, Summary and Statistical Report of 2007 Population and Housing Census, UNFPA, Addis Ababa, Ethiopia, 2008.

[16] Cheesbrough M (2006). District Laboratory Practice in Tropical Countries Part 2. Second Edition. Cambridge University Press.

[17] WHO (2012). Global Tuberculosis Report.

[18] Gebre D, Mimano LN (2010). Prevalence of smear positive pulmonary tuberculosis among patients attending Seka Health Center, Jimma, Oromia Region, Ethiopia. East Afr J Public Health; 7:268-73.

[19] Lemos ACM, Matos ED, Bittencourt CN (2009). Prevalence of active and latent TB among inmates in a prison hospital in Bahia, Brazil. J Bras Pneumol ;35:63-68

[20] Assefzadeh M, Barghi RG, Shahidi ShS (2009).Tuberculosis case--finding and treatment in the central prison of Qazvin province, Islamic Republic of Iran. East Mediterr Health J; 15:258-63.

[21] Shah SA, Mujeeb SA, Mirza A, Nabi KG, Siddiqui Q (2003). Prevalence of pulmonary tuberculosis in Karachi juvenile jail, Pakistan. East Mediterr Health J; 9:667-74.

[22] Banda HT, Gausi F, Harries AD, Salaniponi FM (2009). Prevalence of smear-positive pulmonary tuberculosis among prisoners in Malawi: a national survey. Int J Tuberc Lung Dis; 13:1557-9.

[23] Moges B, Amare B, Asfaw F, Tesfaye W, Tiruneh M, Belyhun $\mathrm{Y}$ etal(2012).Prevalence of smear positive pulmonary tuberculosis among prisoners in North Gondar Zone Prison, northwest Ethiopia. BMC Infect Dis; 12:352.

[24] Zerdo Z, Medhin G, Worku A, Ameni G (2014). Prevalence of Pulmonary Tuberculosis and Associated Risk Factors in Prisons of Gamo Goffa Zone, South Ethiopia: A CrossSectional Study. American Journal of Health Research; 2: 291297. 